\title{
Joint Hypermobility in Women with Cesarean Section
}

\author{
Ziad S. Al-Rawi ${ }^{1}$, Layla Abbosh Hasan ${ }^{2}$, Faiq I. Gorial ${ }^{1}$ \\ ${ }^{I}$ Department of Medicine, College of Medicine, Baghdad University, Baghdad, Iraq \\ ${ }^{2}$ Baghdad Teaching Hospital, Rheumatology Unit, Baghdad, Iraq
}

\begin{abstract}
:
Background: Delivery modalities are importantobstetrical issues. Joint hypermobility (JHM) is a common clinical condition with striking female predominance. The aim of the study was to assess JHM in women with cesarean section (CS).
\end{abstract}

Methods: This case control study included 100 women with CS and 100 women with normal vaginal delivery (NVD) matched in age and BMI. Joint mobility was measured by a blinded observer according to Beighton score. Women with joint mobility score $\geq 4$ were hypermobile.

Results: JHM was significantly less in women with CS than NVD group [8 (24.2\%) vs 25 (75.8\%), OR (95\% $C I), P=0.002]$.Total joint mobility score was significantly less in CS group (111) than in NVD group (197) $(p=0.002)$.Joint mobility score at cut off $\leq 3$ had accuracy of $59 \%$, with positive predictive value $55 \%$, sensitivity (92\%), and specificity (25\%).

Conclusions: Joint mobility was reduced in women with CS. Joint mobility score at cut off $\leq 3$ had moderate accuracy and high sensitivity to diagnose women who may need CS. This may suggest that women with more hypermobile joints may be a prognostic and facilitating factorof spontaneous vaginal birth.

Keywords: Joint hypermobility, Cesarean section, Beighton score.

\section{Introduction}

Cesarean sections (CSs) rates have progressively increased in many countries, particularly among developing countries [1] and a large number of CSs currently performed without medical indications are associated with higher risks than benefits [2]. The main reasons for the rise in CS rate are private service as well as some requests by mothers [3]. Joint hypermobility (JHM) is a common, heritable trait observed predominantly in women and characterized by musculoskeletal symptoms with widespread joint laxity, independent of a systemic rheumatoid disease [4].

Studies have suggested that JHM is associated with pelvic floor disorders However, It is unknown whether joint laxity might influence obstetrical outcomes. Indeed, it has long been recognized that joint laxity increases over the course of pregnancy [5-7], allowing the bony pelvis to adapt to accommodate vaginal birth. It is plausible that women with hypermobility syndrome may be at lower risk for cephalopelvic disproportion. This study was designed to assess cesarean section (CS) in women with JHM.

\section{Study design}

\section{Methods}

This case control study was conducted in Gynecology and Obstetrics Department in Baghdad Teaching Hospital. One hundred women delivered with CS and 100 women with NVD were studiedconsecutively. The study protocol was approved by the Ethics Committee of Baghdad University of Medical Sciences, and a written informed consent was obtained from each participant.

\section{Sample selection}

Only women with previous or current CS due to cephalopelvic disproportion and obstructed labor were included in the study. Patients were excluded from the study if their CS were due to pelvic tumor, cervical stenosis or double uterus, fetal malpresentations, abnormal uterine action, antepartum hemorrhage, other maternal diseases, and fulminating pregnancy induced hypertension, or if it is due to any of the fetal causes for CS.

\section{Clinical evaluation}

Full history was taken from all individuals including age, parity, previous obstetric history, history of diabetes mellitus and hypertension associated with pregnancy, pre-eclamptic toxemia, previous CS with its indication, and the indication for the current CS. Body mass index (BMI) was measured according the equation BMI $=$ weight $/$ height $^{2}$. 
The degree of joint mobility in both groups was recorded on the day three to five after delivery according to Beighton method by a blinded observer [8] with slight modification (Bending forward was not done for all patients in the two groups due to the difficulty of doing the test in the CS group).Patients who recorded 4 or more scores were considered hypermobile.

\section{Statistical analysis}

Statistical software (SPSS version 22, IBM, USA) was used for data analysis. Kolmogorov-Smirnov test was used to assess the normal distribution of continuous variables. Descriptive statistics were presented as mean \pm standard deviation (SD) for normally distributed continuous variables and as numbers and percentages (\%) for categorical variables. Statistical significance of differences between 2 groups of normally distributed continuous variables was assessed using Student's t test.Chi square test was used to assess the significance of difference between categorical variables.P value $<0.05$ was considered statistically significant.

\section{Results}

A total of 200women were involved in the study. Of those, 100 had CS and 100 had NVD. There was no statistical difference between age and BMI of women with CS and NVD group (27.8 \pm 0.448 vs $28.4 \pm 0.45$, $\mathrm{p}=0.46 ; \quad 22.7 \pm 0.419$ vs $23.1 \pm 0.421, \mathrm{p}=0.47$ respectively).

Patients with joint hypermobility were significantly less in the CS group than in NVD group $8(8 \%)$ vs $25(75.8 \%), \mathrm{p}=0.002, \mathrm{OR}=0.26,95 \% \mathrm{CI}=0.11-0.61)$ ) as shown in table 1 . Total joint mobility score was significantly less in CS group (111) than in NVD group (197) $(\mathrm{p}=0.002)$ as in figure1.

The ROC analysis ofjointmobility score revealed that AUC was (0.60) and significantly different from the 0.5 area expected for an equivocal test $(\mathrm{p}=0.03$, Figure 2$)$. The optimum cut-off value for this score was $\leq 3$ positive criteria. This new score had high sensitivity (92\%), moderate accuracy of $59 \%$ and would establish the diagnosis of women who need CS with $55 \%$ confidence (Table 2).

Table1:Joint mobility in the study group

\begin{tabular}{lcccc}
\hline Joint mobility & CS group & NVD group & P & OR(95\% CI) \\
& $\mathrm{n}(\%)$ & $75)$ & $0.002 *$ & $0.26(0.11-0.61)$ \\
\hline Normal mobility & $92(55.1 \%)$ & $75(44.9 \%)$ & & \\
Hypermobility & $8(24.2 \%)$ & $25(75.8 \%)$ & & \\
\hline
\end{tabular}

$\mathrm{CS}$, cesarean section; NVD, normal vaginal delivery; ${ }^{*} \mathrm{p}<0.05$ is significant; OR, odd ratio; CI, confidence interval.

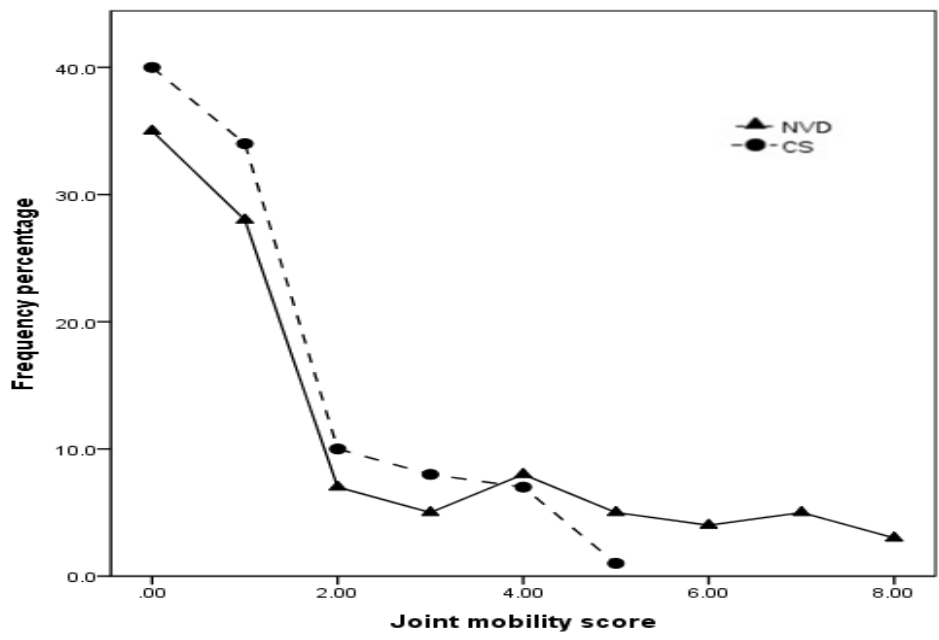

Fig.1 Joint mobility score in the study group 


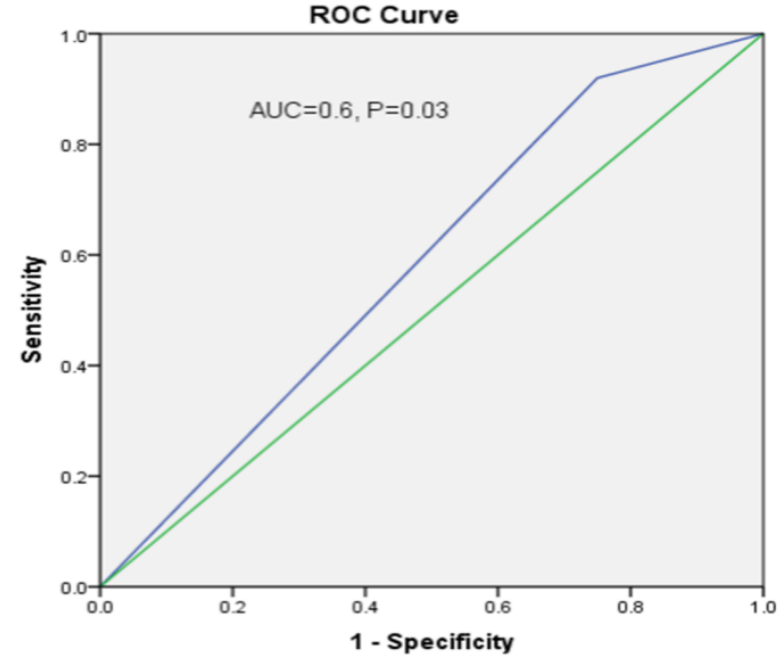

Figure2: ROC curve showing the performance of mobility score (count of positive criteria) in the diagnosis of CS patients differentiating it from NVD (healthy controls).

Table2: Validity parameters of joint mobility score when used as a test in diagnosis ofwomen who may need CS differentiating it from NVD

\begin{tabular}{llllll}
\hline Positive if $\leq$ cut-off value & Sensitivity & Specificity & Accuracy & PPV & NPV \\
\hline Joint mobility score $\leq 3$ & $92 \%$ & $25 \%$ & $59 \%$ & $55 \%$ & $76 \%$ \\
\hline
\end{tabular}

$\mathrm{PPV}$, positive predictive value; NPV, negative predictive value

\section{Discussion}

This study aimed to assess joint mobility in women with CS. Interestingly, it showed that JHM was significantly less in women with CS group than NVD group. This is a statistically significant and clinically important because it may indicate that patients with hypermobility are more prone to NVD than CS.

Patients with hypermobility have been shown to have an increased concentration of type III procollagen [9]. The high collagen content in the musculotendinous pelvic floor can result in pelvic floor problems in women with pelvic floor relaxation during pregnancy in addition to laxity of peripheral joints [1012]. The Joint laxity may allow more easy passage of the fetal head through the pelvis. Thus, from an obstetrical perspective, joint hypermobility may be advantageous to facilitate spontaneous vaginal birth [13].

Jones and $\mathrm{Ng}$ [14] suggested that normal vaginal delivery can be encouraged in Joint hypermobility syndrome of Ehlers-Danlossyndromehypermobilitytype (JHS/EDS-HT). Castori et al [15] evaluated obstetricimplications of the JHS/EDS-HT in 82Italianpatients in two centers and demonstrated that CS was less than NVD in hypermobile patients( $22.3 \%$ vs $72.2 \%)$.Recently,Knoepp et al [16] investigated the association between joint hypermobility syndrome and obstetrical outcomes and found that women with hypermobility were associated with decreased odds of cesarean sections after complete cervical dilation or operative vaginal delivery [odds ratio $(\mathrm{OR})=0.51 ; 95 \%$ confidence interval $(\mathrm{CI}): 0.27-0.95]$. On the other side, another study found that JHS/EDS-HTwho had an exacerbation of systemic and/or musculoskeletal symptoms during pregnancy might necessitate CS [17].These unresolved controversies on the choice between cesarean and vaginal delivery in JHS/EDS-HT are presumably related to the shortage of studies on consistent numbers of patients with homogenous phenotypes.

Furthermore; the new joint mobility score we found was a valid measure and may be clinically important score in early diagnosis of women who may need CS and differentiating them from NVD in suspected cases.

The small sample size of the current study may be a limitation. This can be resolved by a larger scale studies. However, up to the best of our knowledge this is the first case controls study in Iraq and it is noteworthy that the finding is practically important to predict the delivery modality in hypermobile patients.

In conclusion, CS was negatively associated with women who had joint hypermobility. This may suggest that hypermobile joints are a facilitating factor for NVD and not a predisposing factor for obstructed labor and CS.

\section{Acknowledgments}

We thank all patients for participation in this study 


\section{References}

[1]. Festin MR, Laopaiboon M, Pattanittum P, et al. Caesareansection in fourSouthEastAsiancountries: reasons for, rates, associatedcarepractices and healthoutcomes.BMC Pregnancy Childbirth. 2009 May 9;9:17.

[2]. Charoenboon C, Srisupundit K, TongsongT.Rise in cesareansectionrateover a 20-yearperiod in a publicsectorhospital in northernThailand. Arch Gynecol Obstet. 2013 Jan;287(1):47-52

[3]. Niino Y. The increasing cesarean rate globally and what we can do about it. Biosci Trends 2011; 5(4):139-150

[4]. Remvig L, Jensen DV, Ward RC. Epidemiology of general joint hypermobility and basis for the proposed criteria for benign joint hypermobility syndrome: review of the literature. J Rheumatol 2007; 34:804-9

[5]. Aydeniz A, Dikensoy E, Cebesoy B, et al. The relation between genitourinary prolapse and joint hypermobility in Turkish women. Arch Gynecol Obstet. 2010; 281:301-4.

[6]. Calguneri M, Bird HA, Wright V. Changes in joint laxity occurring during pregnancy. Ann Rheum Dis. 1982; 41(2):126-128. [PubMed: 7073339]

[7]. Marnach ML, Ramin KD, Ramsey PS, et al. Characterization of the relationship between joint laxity and maternal hormones in pregnancy. Obstet Gynecol. 2003; 10:331-5.

[8]. Beighton PH, Solomon L, Soskelne CL. Articular mobility in an African population. Ann Rheum Dis 1973;32:413-8

[9]. Knuuti E, Kauppila S, Kotila V, et al. Genitourinary prolapse and joint hypermobility are associated with altered type I and III collagen metabolism. Arch Gynecol Obstet2011;283:1081-5.

[10]. Swift SE. The distribution of pelvic organ support in a population of female subjects seen for routine gynaecological health care. Am J Obstet Gynecol2000;183:277-85.

[11]. Swift SE, Woodman P, O’Boyle A, et al. Pelvic Organ Support Study (POSST): the distribution, clinical definition and epidemiology of pelvic organ support defects. Am J Obstet Gynecol2005;192:795-806.

[12]. Sliecker-ten HMCP, Vierhout M, Bloembergen H, Schoenmaker G. Distribution of pelvic organ prolapse in a general population: prevalence severity, etiology and relation with function of pelvicfloor muscles. Abstract presented at the joint meeting of ICS and IUGA, August 25-27, Paris, France. 2004.

[13]. Knoepp LR, McDermott KC, Muñoz A, et al.Joint hypermobility, obstetrical outcomes, and pelvic floor disorders. IntUrogynecol J. 2013 May;24(5):735-40

[14]. Jones TL, $\mathrm{Ng} \mathrm{C.} \mathrm{2008.} \mathrm{Anaesthesia} \mathrm{for} \mathrm{caesarean} \mathrm{section} \mathrm{in} \mathrm{a} \mathrm{patient} \mathrm{with} \mathrm{Ehlers-Danlos} \mathrm{syndrome} \mathrm{associated} \mathrm{with} \mathrm{postural}$ orthostatic tachycardia syndrome. Int J ObstetAnesth 17:365-369.

[15]. Castori $\mathrm{M}^{1}$, Morlino S, Dordoni C, et al. Gynecologic and Obstetric Implications of the Joint Hypermobility Syndrome (a.k.a. Ehlers-Danlos Syndrome Hypermobility Type) in 82 Italian Patients. Am J Med Genet A. 2012 Sep;158A(9):2176-82. doi: 10.1002/ajmg.a.35506. Epub 2012 Jul 27.

[16]. Knoepp LR, McDermott KC, Muñoz A, et al. Joint hypermobility, obstetrical outcomes, and pelvic floor Disorders. IntUrogynecol J. 2013 May;24(5):735-40. doi: 10.1007/s00192-012-1913-x. Epub 2012 Aug 17.

[17]. Golfier F, Peyrol S, Attia-Sobol J, Marret H, Raudrant D, Plauchu H. 2001. Hypermobility type of Ehlers-Danlos syndrome: Influence of pregnancies. Clin Genet 60:240-241 